\title{
Cytotoxic, Cellular Antioxidant, and Antiglucuronidase Properties of the Ethanol Leaf Extract from Bulbine asphodeloides
}

\author{
Wilfred Otang-Mbeng $\mathbb{D}$ and Idowu Jonas Sagbo \\ School of Biology and Environmental Sciences, University of Mpumalanga, Private Bag X11283, Mbombela 1200, South Africa \\ Correspondence should be addressed to Idowu Jonas Sagbo; jonas.sagbo@ump.ac.za
}

Received 3 December 2020; Revised 24 March 2021; Accepted 8 April 2021; Published 14 April 2021

Academic Editor: Nirmal Kumar Sarkar

Copyright (c) 2021 Wilfred Otang-Mbeng and Idowu Jonas Sagbo. This is an open access article distributed under the Creative Commons Attribution License, which permits unrestricted use, distribution, and reproduction in any medium, provided the original work is properly cited.

\begin{abstract}
Bulbine asphodeloides (L.) Spreng (Xanthorrhoeaceae family), popularly known in South Africa as "ibhucu" or "Balsamkopieva," is a perennial plant traditionally used to treat skin diseases, including sunburns, rough skin, dressing burns, itches, and aging. The present study reports the cytotoxic, cellular antioxidant, and antiglucuronidase properties of the ethanol leaf extract from B. asphodeloides. The cytotoxic effect of the plant extract on human dermal fibroblast (MRHF) cells was evaluated by the bisBenzamide H 33342 trihydrochloride/propidium iodide (Hoechst 33342/PI) dual-staining method. A validated biological cellbased assay was used to determine the cellular antioxidant activity of the extract. The antiglucuronidase and metal chelating activities were evaluated using standard in vitro methods. Lipopolysaccharide- (LPS-) induced RAW 264.7 cell model was used to determine the anti-inflammatory effect of the plant extract, and the immune-modulatory activity was performed using RAW 264.7 cells. The extract demonstrated no cytotoxic effect towards the MRHF cells at all the tested concentrations. Furthermore, the extract also possessed significant cellular antioxidant and antiglucuronidase activities, but a weak effect of metal chelating activity in a dose-dependent manner. However, the extract showed no significant anti-inflammatory and immune-stimulatory activities. Overall, the results showed that $B$. asphodeloides may be a useful therapeutic agent for the treatment of skin diseases, therefore supporting its ethnomedicinal usage.
\end{abstract}

\section{Introduction}

Skin is more than a fleshy surface for tattoos, pimples, and wrinkles. It is the body's largest organ, with a total area of approximately 20 square feet, which plays a very significant function by protecting the body from microorganisms, helps regulate body temperature, and permits the sensations of pain, cold, heat, and touch. The skin is perhaps the most susceptible component of our body, and keeping healthy skin is important for a healthy body. It is a well-known fact that day-to-day exposure of human skin to the external environment leads to numerous skin diseases, such as sunburn marks, acne, and pigmentation [1]. In broad terms, skin diseases represent about $34 \%$ of all the diseases faced worldwide [2]. They are abundant and often occurring health problems affecting all ages from the neonates to the elderly and cause harm in several ways [3]. Skin diseases now occur as a main health encumbrance in both developed and developing countries. Despite the high frequency of skin diseases globally, mortality attributed to them so far has been relatively low, frequently persistent, and difficult to treat [4]. According to the World Health Organization, every year, approximately 180,000 people die from burns (fire-related burns) globally [5]. In South Africa, more than 19,500 burnrelated deaths are reported every year, and they rank among the 15 leading causes of death among adolescents between the ages of 5-29 years [6]. This prevalence is driven by negative impact factors, including the inflow of people to urban areas, poor electrification of homes in low-income communities, and the use of paraffin and biomass fuels as the primary energy sources.

Human beings have been using natural resources empirically for skin care and also modifying their physical appearance. Medicinal plants have been extremely sought 
after to treat dermatological ailments due to their ability to treat burns, discontinue bleeding, accelerate wound healing, and lessen other skin conditions [7]. They are particularly significant and rich in antioxidant molecules that could impede oxidative stress or redox imbalances and alleviate the risk of emerging skin diseases [8]. However, the use of medicinal plants for dermatological inflictions has not been given the attention it so rightly deserves. This is astonishing as many plant species used traditionally for the treatment of skin conditions have not been adequately studied for their pharmacological efficacy.

Bulbine asphodeloides (L.) Spreng is a perennial herb from the family of Xanthorrhoeaceae (formerly Asphodelaceae), locally known as "Copaiva," "intelezi," "ibhucu," or "Balsamkopieva" in South Africa $[9,10]$. It is commonly used for the treatment of skin diseases in most parts of South Africa. Traditionally, the leaf gel is applied topically to wounds, sunburns, rough skin, and dressing burns $[11,12]$. About 10 metabolites have been identified in B. asphodeloides by gas chromatography-mass spectrometry (GC-MS), and these were mostly sesquiterpenes $(33.37 \%)$, fatty acid esters (12.62\%), and diterpenes (8.03\%) [13]. The phytochemical components identified from $B$. asphodeloides include anthraquinones and glycosides [14]. The root extract of $B$ asphodeloides was reported to display weak inhibitory activity against Erwinia carotovora, a Gram-negative bacterium [15]. The ethnomedicinal uses of B. asphodeloides for the treatment of skin diseases provide justification for the undertaking of this present study to investigate the cytotoxic, cellular antioxidant and antiglucuronidase properties of the ethanol leaf extract from $B$ asphodeloides. For this reason, this study set out to provide scientific understanding of its benefits and justification for its ethnomedicinal uses for the treatment of skin diseases.

\section{Materials and Methods}

2.1. Chemicals and Reagents. All the cell lines used in this study were purchased from Celonex (South Africa). The cell culture medium (DMEM, RPMI), phosphate-buffered saline (PBS), and trypsin were obtained from Hyclone, Logan, UT, USA. Fetal bovine serum (FBS) was obtained from Biowest (Logan, UT, USA). Hoechst, propidium iodide, and $2^{\prime}, 7^{\prime}$ dichlorofluorescin diacetate (DCFDA) were purchased from Sigma-Aldrich (St. Louis, MO, USA). The Annexin-FITC was obtained from MACS Miltenyi Biotec (Cologne, Germany), whereas enzymes, substrate, and other chemicals were obtained from Sigma-Aldrich (St. Louis, MO, USA).

2.2. Plant Material and Extraction. The fresh and mature B. asphodeloides leaves were collected in January 2020 from the Amatole district of the Eastern Cape province of South Africa. The voucher specimen (voucher no. BUR-2024) was authenticated and kept at the University of Fort Hare's Giffen Herbarium. For the extraction process, the powdered plant $(30 \mathrm{~g})$ was soaked in ethanol $(500 \mathrm{~mL})$ at room temperature for $24 \mathrm{~h}$. Thereafter, the resulting mixture was filtered and then concentrated to dryness using a rotary evaporator (RVO 004; Ingos, Prague, Czech Republic) to obtain a dried extract $(9.05 \%$ dry extract) [16].

2.3. Beta-Glucuronidase Assay. The test sample $(10 \mu \mathrm{L})$ and positive control, silymarin $(48 \mu \mathrm{g} / \mathrm{mL})$, were pipetted into the wells of a 96-well plate. Then, $40 \mu \mathrm{L}$ enzyme solution was added to each well except those representing background and then incubated for $20 \mathrm{~min}$ at $37^{\circ} \mathrm{C}$. Subsequently, $50 \mu \mathrm{L}$ substrate solution containing solubilize $7.88 \mathrm{mg} \beta$-D-glucuronide-PNA (Sigma N1627) and $5 \mathrm{~mL}$ assay buffer (PBS containing 5\% DMSO and $0.05 \%$ BSA) was added to the test well and background well, respectively, and then incubated for further $30 \mathrm{~min}$ at $37^{\circ} \mathrm{C}$. After the incubation period, $5 \mu \mathrm{L}$ stop solution $(0.1 \mathrm{M} \mathrm{NaOH})$ was then added, and the absorbance was read at $410 \mathrm{~nm}$.

2.4. Metal Ion Chelating Assay. The test sample $(10 \mu \mathrm{L})$ with various concentrations was mixed with $200 \mu \mathrm{L}$ deionised water, $20 \mu \mathrm{L}$ ferrous sulphate $\left(\mathrm{FeSO}_{4}\right)$, and $40 \mu \mathrm{L}$ ferrozine. Thereafter, the resulting mixture was incubated at room temperature for $10 \mathrm{~min}$, and the absorbance was read at $560 \mathrm{~nm}$. EDTA $(4 \mu \mathrm{g} / \mathrm{mL})$ was used as a positive control.

2.5. Cell Culture Condition. The human foreskin fibroblast (MRHF) cells were maintained in culture dishes $(10 \mathrm{~cm})$ in complete DMEM (low glucose) supplemented with 10\% FBS, while the RAW 264.7 cells were maintained in culture dishes $(10 \mathrm{~cm})$ in RPMI supplemented with $10 \%$ FBS. All cell cultures were incubated at $37^{\circ} \mathrm{C}$ in a humidified atmosphere with $5 \% \mathrm{CO}_{2}$.

2.6. Cytotoxicity. The cytotoxic activity of B. asphodeloides on MRHF cells was assessed by the Hoechst 33342/PI dualstaining method [17]. Cells were seeded in a 96 well-plate at a density of 8000 cells/well using aliquots $(100 \mu \mathrm{L})$ and left to attach overnight. The treatment concentrations ranged from 25 to $100 \mu \mathrm{g} / \mathrm{mL}$ for the plant extract. After incubation for $24 \mathrm{~h}$ at $37^{\circ} \mathrm{C}$ in a humidified incubator with $5 \% \mathrm{CO}_{2}$, the treatment medium was removed and replaced with $50 \mu \mathrm{L}$ of staining solution ( $5 \mathrm{~mL}$ PBS with $\mathrm{Ca}^{2+}$ and $\mathrm{Mg}^{2+}, 2 \mu \mathrm{L}$ Hoechst $33342(10 \mathrm{mg} / \mathrm{mL}$ in DMSO), and $50 \mu \mathrm{L}$ Annexin $\mathrm{V}$-FITC reagent) and incubated for $15 \mathrm{~min}$ at $37^{\circ} \mathrm{C}$. Then, $50 \mu \mathrm{L}$ of propidium iodide (PI) $(2 \mu \mathrm{g} / \mathrm{mL})$ was added, and the cells were then imaged using the ImageXpress Micro XLS Widefield High-Content Analysis System Molecular Devices (Molecular Devices ${ }^{\circledR}$, San Jose, CA, USA). Nine image sites per well were acquired using FITC, DAPI, and Texas Red filters, and the images were analysed using MetaXpress ${ }^{\circledR}$ High-Content Image Acquisition and Analysis Software (Molecular Devices ${ }^{\circledR}$, San Jose, CA, USA).

2.7. Cellular Antioxidant Assay. MRHF cells were seeded in a 96-well plate at a density of 8000 cells per well and allowed to reach complete confluence. Two days after confluence, the spent medium was removed by aspiration and then washed with Hank's Balanced Salt Solution (HBSS) to remove 
serum. Then, $50 \mu \mathrm{L}$ of the plant extract $(12.5,25,50,100$, and $200 \mu \mathrm{g} / \mathrm{mL}$ ) or resveratrol (positive control) and $50 \mu \mathrm{L}$ DCFDA $(25 \mu \mathrm{M})$ were added. After incubation for $1 \mathrm{~h}$ at $37^{\circ} \mathrm{C}$, the cells were washed twice with HBSS and then further washed with PBS. Thereafter, $100 \mu \mathrm{L}$ tert-butyl hydroperoxide $(200 \mu \mathrm{M})$ was added, and the fluorescence intensity was then measured at $485 \mathrm{~nm}$ (excitation) and $440 \mathrm{~nm}$ (emission) at $10 \mathrm{~min}$ intervals for $90 \mathrm{~min}$.

2.8. Anti-Inflammatory Assay. Anti-inflammatory activity was performed as previously reported [18]. The murine peritoneal macrophage cells (RAW 267.4) were seeded in a 96-well plate at a density of $1 \times 10^{5}$ cells per well and allowed to attach overnight. The spent medium was removed and replaced with $1 \mu \mathrm{g} / \mathrm{mL}$ bacterial lipopolysaccharide (LPS) and five concentrations of the plant extract $(6.5,12.5,25,50$, and $100 \mu \mathrm{g} / \mathrm{mL})$ or positive control, aminoguanidine $(7 \mu \mathrm{g} /$ $\mathrm{mL}$ ), and then incubated for $18 \mathrm{~h}$ at $37^{\circ} \mathrm{C}$. To measure the nitric level, the spent medium $(50 \mu \mathrm{L})$ was removed and added to an equal volume of Griess reagent. The absorbance was then measured at $540 \mathrm{~nm}$. Cell viability was determined using the MTT assay [19].

2.9. Immune-Stimulatory Potential. The RAW 267.4 macrophage cells were seeded in a 96-well plate at a density of $1 \times 10^{5}$ cells per well and allowed to attach overnight. The spent medium was removed and replaced with varying concentrations $(12.5,25,50,100$, and $200 \mu \mathrm{g} / \mathrm{mL})$ of the plant extract or positive control, bacterial lipopolysaccharide $(1 \mu \mathrm{g} / \mathrm{mL})$, and then incubated for $18 \mathrm{~h}$ at $37^{\circ} \mathrm{C}$. To measure the nitric level, $50 \mu \mathrm{L}$ of the spent medium was removed and added to the Griess reagent ( $50 \mu \mathrm{L}$ ), and the absorbance was then observed at $540 \mathrm{~nm}$.

2.10. Statistical Analysis. The data were statistically analysed by means of Student's $t$-test (two-tailed paired). Three replicates of each test sample (ethanol extract) were compared with three replicate values of the controls.

\section{Results}

3.1. Beta-Glucuronidase Activity. The results of beta-glucuronidase inhibition are shown in Figure 1 which revealed significant inhibitory activity against the bacterial $\beta$-glucuronidase enzyme in a dose-dependent manner with the greatest inhibition recorded at the concentration of $400 \mu \mathrm{g} /$ $\mathrm{mL}$ compared to the control. Silymarin, used as a positive control, demonstrated $61.7 \%$ inhibition of bacterial $\beta$-glucuronidase activity.

3.2. Metal Ion Chelating Activity. To assess the preventive ability of the B. asphodeloides extract to limit chemical reactivity on the skin surface, inhibition of metal ion chelating activity was investigated. The result showed dose-dependent metal ion chelating activity (Figure 2); however, statistical significance was only reached at the higher concentrations

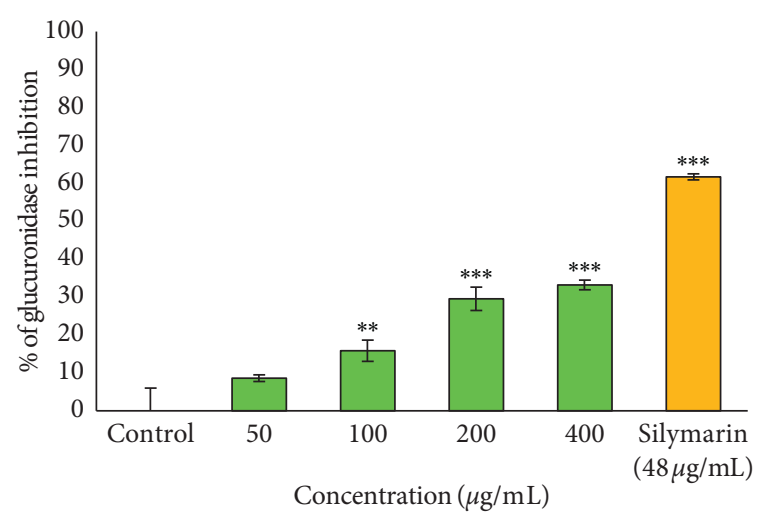

FIGURE 1: Inhibitory effect of the ethanol extract of B. asphodeloides on beta-glucuronidase activity. Data are presented as the mean $\pm \mathrm{SD}(n=3) . * * P<0.01$ and $* * * P<0.001$ compared to the control.

(100 and $200 \mu \mathrm{g} / \mathrm{ml}$ ) as compared to the control, although weak relative to the positive control, EDTA.

3.3. Cytotoxicity. The cytotoxic effect of the B. asphodeloides extract towards MRHF cells was assessed using the Hoechst 33342/PI dual-staining method. Treatment of MRHF cells with the B. asphodeloides extract showed that the extract was not cytotoxic to the cell lines at the tested concentrations (Figure 3). Also, there was no significant $(P<0.001)$ cytotoxicity at all the tested concentrations as indicated by the percentage of live cells (decrease in the percentage of apoptotic cells as well as a significant increase in the relative cell counts). It was also evident that there was no significant $(P<0.001)$ increase in the percentage of late apoptosis/ necrosis cells across all the tested concentrations (25-100 $\mu \mathrm{g} /$ $\mathrm{mL}$ ) as compared to the control cells. On the contrary, melphalan $(31 \mu \mathrm{g} / \mathrm{mL})$, used as a positive control, exhibited a significant cytotoxicity (decrease in the percentage of live cells as well as increase in the percentage of apoptotic cells) compared to the trend seen in both the extract and the control.

3.4. Cellular Antioxidant Activity. The cellular antioxidant activities of $B$. asphodeloides are evaluated by the cellular antioxidant activity (CAA) assay using the MRHF cells. The degree of protection of the tested plant extract against the cellular conversion of DCF is illustrated in Figure 4. Included also is resveratrol, a known antioxidant compound. The results recorded indicated that the extract $(12.5 \mu \mathrm{g} /$ $\mathrm{mL}-200 \mu \mathrm{g} / \mathrm{mL}$ ) exhibited significant antioxidant protection in a dose-dependent manner. At the highest tested concentration $(200 \mu \mathrm{g} / \mathrm{mL})$, the effect of the extract was higher than that of the control, but less marked compared to the positive control, resveratrol.

3.5. Anti-Inflammatory Assay (NO Production by LPSActivated RAW 264.7). The result of the NO production by LPS-activated RAW 264.7 macrophages shows that the plant extract demonstrated no significant inhibition of NO 


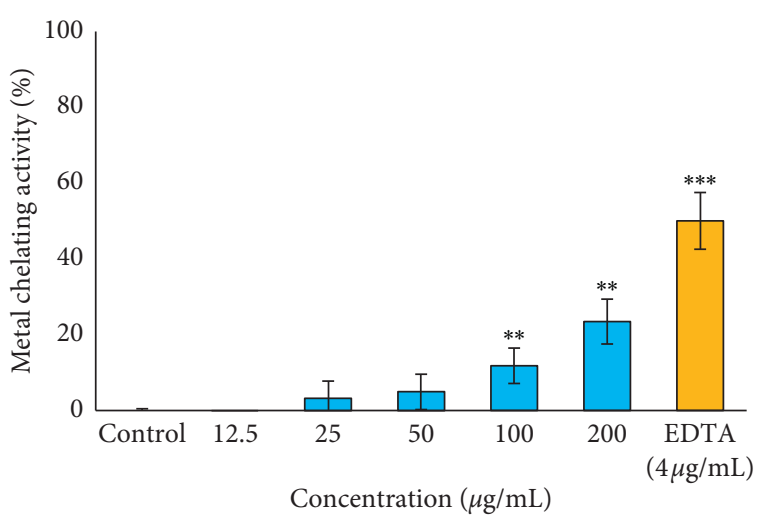

FIGURE 2: Inhibitory effect of the ethanol extract of $B$. asphodeloides on metal ion chelating activity. Data are presented as the mean \pm SD $(n=3) . * * P<0.01$ and $* * * P<0.001$ compared to the control.

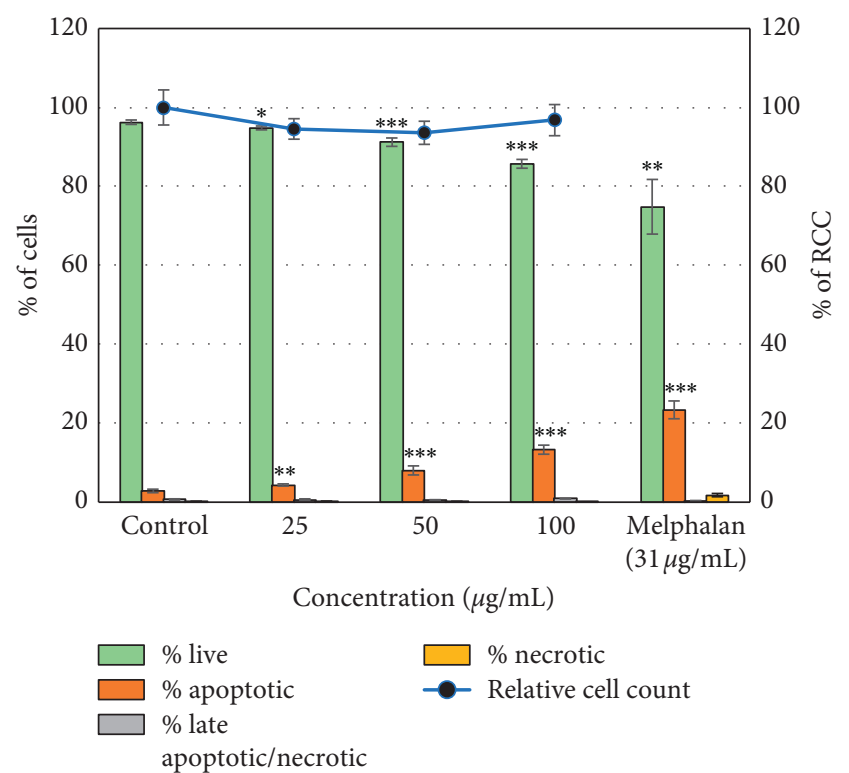

Figure 3: The cytotoxic effect of the B. asphodeloides ethanol leaf extract towards the human dermal fibroblast (MRHF). Data are presented as the mean \pm SD $(n=3) . * P<0.05, * * P<0.01$, and $* * * P<0.001$ compared to the control.

production and noncytotoxicity towards activated RAW 264.7 at all the tested concentrations $(6.25-100 \mu \mathrm{g} / \mathrm{mL})$ (Figure 5). By contrast, the positive control, aminoguanidine $(7 \mu \mathrm{g} / \mathrm{mL})$, displayed better inhibition of NO production than the extract and the untreated control.

3.6. Immune-Stimulatory Potential. The result of the immune-stimulatory potential of the $B$. asphodeloides extract is shown in Figure 6. The result revealed that the extract exhibited no meaningful indication of immune-stimulatory activity. Although some of the higher concentrations revealed statistically significant levels of nitrite in the culture medium, these values are too low to be considered physiologically relevant. Lipopolysaccharides, used as the positive control, increased nitrite production in the culture medium as compared to both the extract and the control.

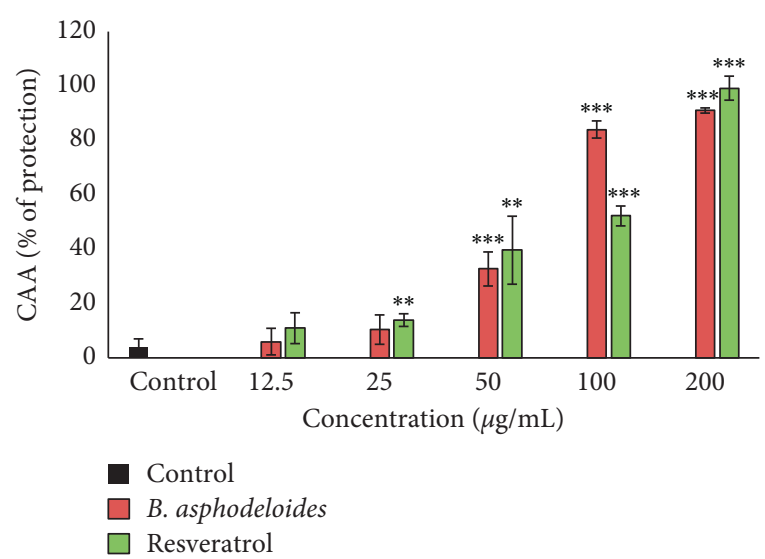

FIgURE 4: Cellular antioxidant activity of the ethanol extract of B. asphodeloides. Data are presented as the mean $\pm \mathrm{SD}(n=3)$. $* * P<0.01$ and $* * * P<0.001$ compared to the control. CAA: cellular antioxidant assay.

\section{Discussion}

$\beta$-Glucuronidase is a prominent exoenzyme responsible for unpleasant body odour. It plays a significant role by catalysing the hydrolysis of $\beta$-glucuronide conjugates of exogenous and endogeneous compounds in the body [20]. Inhibitors of this enzyme are thus considered for cosmetic products aiming to reduce body odour. In this study, the plant extract showed significant inhibition of bacterial $\beta$ glucuronidase activity in a moderate dose-dependent manner. Report has shown that body odour can thus be combated by limiting the bacterial decomposition of apocrine sweat, either by preventing the sweat formation (antiperspirant), eliminating skin-resident bacteria, or by inhibiting the enzymes responsible for sweat decomposition [21]. To the best of our knowledge, this is the first study of the effect of the $B$. asphodeloides extract on the $\beta$-glucuronidase enzyme, suggesting its possible use for antiodour applications.

Accumulation of heavy metals on the skin surface can deplete the stratum corneum antioxidant complement, mainly via Fenton chemistry, leading to oxidative stress and the induction of inflammation and barrier dysfunction. Strategies to avoid such effects include the chelation of metal ions to limit chemical reactivity on the skin surface. In this present study, the result of the metal ion chelating activity showed that the B. asphodeloides extract possesses iron chelation activity; however, this activity is relatively weak and only significant at high concentrations. It may however be argued that high concentration would be achievable on the surface of the skin, and thus, the extract may be expected (to some degree) to combat oxidative stress resulting from metal ion-catalysed reactive oxygen species (ROS) formation. Several previous studies have indicated that polyphenols are highly linked with metal chelating abilities due to the presence of hydroxyl and carboxyl groups attached to their structure [22-24]. Polyphenols, powerful metal chelating agents, act by inactivating metal ions by forming a complex with metals thereby preventing the metal ion from 


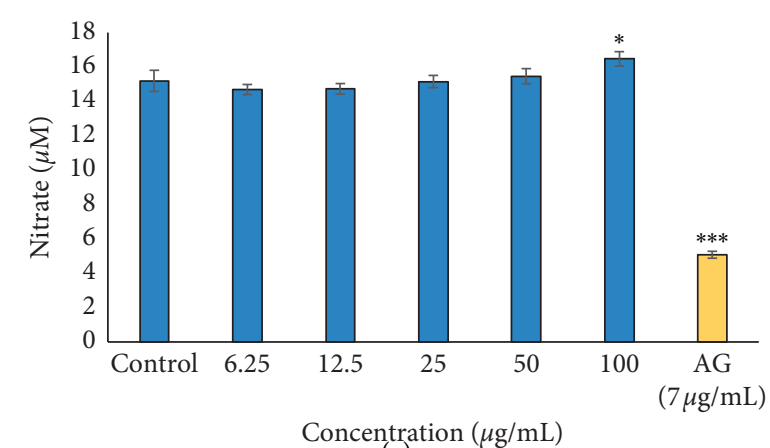

(a)

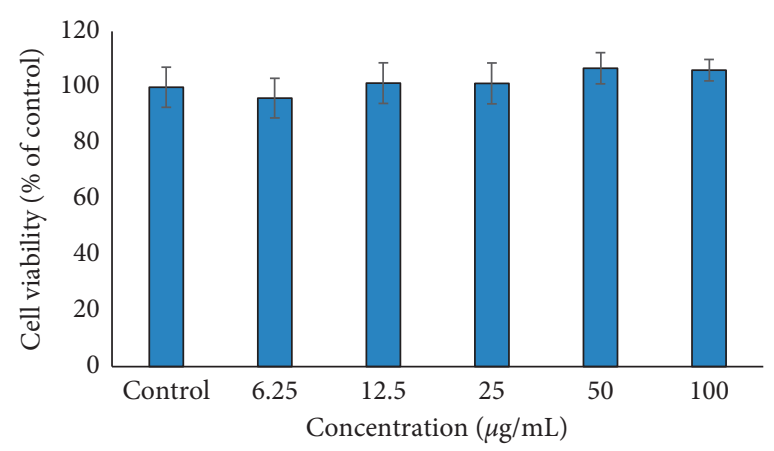

(b)

Figure 5: Effect of the ethanol extract of B. asphodeloides on (a) NO production in LPS-activated RAW 264.7 cells. (b) Corresponding cell viability is also shown. AG: aminoguanidine. Data are presented as the mean $\pm \mathrm{SD}(n=3) . * P<0.05$ and $* * * P<0.001$ compared to the control.

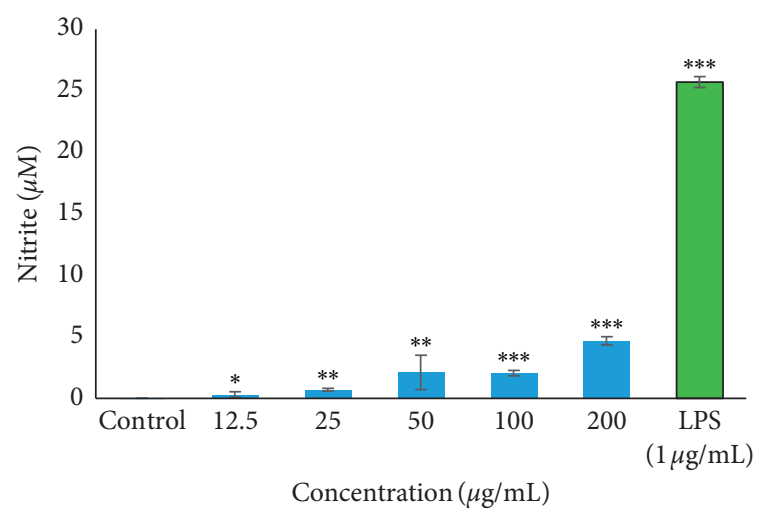

FIGURE 6: Immune-stimulatory potential of the ethanol extract of B. asphodeloides using RAW 264.7 cells. Previous experiment (antiinflammatory assay) has confirmed the absence of toxicity. Data are presented as the mean $\pm \mathrm{SD}(n=3) . * P<0.05, * * P<0.01$, and $* * * P<0.001$ compared to the control.

initiating lipid oxidation $[25,26]$. It could be inferred from this study that the weak iron chelation activity exhibited by the plant extract may be due to the presence of polyphenolic compounds [13], which in turn chelate $\mathrm{Fe}^{2+}$ ions.

Medicinal herbs and their extracts are often erroneously perceived as safe. Therefore, in the evaluation of the therapeutic effects of medicinal plants, it is important to assess their cytotoxicity. The cytotoxicity assay was performed using the Hoechst 33342/PI dual-staining method, and the results indicated that the $B$. asphodeloides extract caused a significant decrease in the percentage of apoptotic cells as well as a significant increase in the RCC at all the tested concentrations, suggesting that the extract is not toxic towards MRHF cells. The cytotoxic effect of $B$. asphodeloides on MRHF cell lines has never been reported. However, studies have been conducted on the cytotoxicity of some Bulbine genus species. A study conducted by Pather [27] revealed that the leaf gel extract of Bulbine frutescens and Bulbine natalensis was not cytotoxic to human dermal fibroblast (MRHF) cells. This observation supports the finding obtained in this study. Therefore, it could be concluded from this study that $B$. asphodeloides may be potentially safe for users.

The cellular antioxidant assay (CAA) measures the net effect of both passive permeability and transporter-assisted permeation and therefore provides a more biologically relevant evaluation of the capacity for an antioxidant to accumulate within a cell. Antioxidants can only protect against oxidative stress if they can reach the environment where reactive oxygen species (ROS) is produced. In this study, the results observed revealed that the extract possesses antioxidant compounds that have cellular bioavailability and can function as an antioxidant within a cellular environment. This is the first study of the cellular antioxidant activity of $B$. asphodeloides, suggesting that the bioactive antioxidant in the plant extract was well engrossed into the MRHF cells thereby exhibiting antioxidant activity. It could be concluded from this study that the $B$. asphodeloides extract may be advantageous in obliterating oxidative damage instigated by free radicals which plays a major contributory role in skin diseases. Given that both the endpoint probe (DCF) and the initiator of oxidative stress (TBHP) used in this study do not occur naturally, further studies using a model in which both the stressor and endpoint measurement represent genuine biological/natural would be useful to confirm that the cellular antioxidant activity of the extract is indeed biologically relevant.

Nitric oxide (NO) overproduction involves a range of events, including the reaction of free radicals and oxidants associated with physiological disorders, such as acute and chronic inflammatory disease, which leads to tissue damage and organ dysfunction $[24,28]$. In general, the result of this study showed that the B. asphodeloides extract displayed no inhibition of NO production in LPS-stimulated RAW cells. On the contrary, the extract does not display cytotoxicity towards RAW 264.7 cells. Interestingly, this corresponds to the result earlier reported showing that the extract was not toxic towards MRHF cells, which further confirms that the $B$. asphodeloides extract was not toxic to cells. Several 
previous studies have shown that most medicinal plants exhibit good anti-inflammatory effect $[29,30]$. A report from Nguyen et al. [31] showed that the ethanol extract of Lasia spinosa effectively decreased NO production in LPSstimulated RAW 264.7 cells thereby inhibiting inflammation. Another study conducted by Sagbo et al. [32] also indicated that the aqueous extract of Brachylaena elliptica reduced NO production in RAW macrophage cells thereby inhibiting anti-inflammatory activity. These results are in contrast to the findings observed in this present study, suggesting that $B$. asphodeloides might not be a good candidate for preventing skin inflammation.

Skin aging and diseases such as diabetes are strongly associated with a decline in immune competency, thereby contributing to skin conditions such as poor wound healing. The result of the immune-stimulating potential showed that the $B$. asphodeloides extract exhibited no indication of immune-stimulatory activity at all the tested concentrations; however, this does not rule out the possibility that the extract may have immune-boosting properties at other therapeutic targets.

\section{Conclusion}

The findings in this study indicated that the leaf extract of B. asphodeloides demonstrated no cytotoxic effect towards the MRHF and RAW 264.7 cells, thereby further supporting the safe use of this plant. The extract also possessed a significant cellular antioxidant, antiglucuronidase, and weak effect of metal chelating activities in a dose-dependent manner. However, the B. asphodeloides extract displayed no significant anti-inflammatory and immune-stimulatory activities. Taken together, the results of this present study showed that $B$. asphodeloides may be a useful therapeutic agent for the treatment of skin diseases, therefore supporting its ethnomedicinal usage. Further studies are warranted to isolate and characterize the active components of the plant extract.

\section{Data Availability}

The data used to support the findings of this study are available from the corresponding author upon request.

\section{Conflicts of Interest}

The authors declare that there are no conflicts of interest regarding the publication of this paper.

\section{Acknowledgments}

The authors are grateful for the funding support from the University of Mpumalanga and the National Research Foundation of South Africa. This study was funded by the National Research Foundation (NRF) (Grant no. 105161).

\section{References}

[1] J. English, R. Dawe, and J. Ferguson, "Environmental effects and skin disease," British Medical Bulletin, vol. 68, no. 1, pp. 129-142, 2003.

[2] K. Malik, M. Ahmad, M. Zafar et al., "An ethnobotanical study of medicinal plants used to treat skin diseases in northern Pakistan," BMC Complementary and Alternative Medicine, vol. 19, p. 210, 2019.

[3] N. Tabassum and M. Hamdani, "Plants used to treat skin diseases," Pharmacognosy Reviews, vol. 15, no. 8, pp. 52-60, 2014.

[4] D. Seth, K. Cheldize, D. Brown, and E. E. Freeman, "Global burden of skin disease: inequities and innovations," Current Dermatology Reports, vol. 6, no. 3, pp. 204-210, 2017.

[5] World Health Organization (WHO), Violence and Injury Prevention, World Health Organization (WHO), Geneva, Switzerland, 2020, https://www.who.int/violence_injury_ prevention/en/.

[6] N. Lall and N. Kishore, "Are plants used for skin care in South Africa fully explored?," Journal of Ethnopharmacology, vol. 153, no. 1, pp. 61-84, 2014.

[7] U. Mabona, A. Viljoen, E. Shikanga, A. Marston, and S. Van Vuuren, "Antimicrobial activity of southern African medicinal plants with dermatological relevance: from an ethnopharmacological screening approach, to combination studies and the isolation of a bioactive compound," Journal of Ethnopharmacology, vol. 148, no. 1, pp. 45-55, 2013.

[8] M. Abbas, F. Saeed, F. M. Anjum et al., "Natural polyphenols: an overview," International Journal of Food Properties, vol. 20, pp. 1-11, 2016.

[9] Kumbula Indigenous Garden, A Database of Indigenous South African Flora, Kumbula Indigenous Garden, Bathurst, South Africa, 2020, https://kumbulanursery.co.za/plants/bulbineasphodeloides.

[10] A. P. Dold and M. L. Cocks, "Preliminary list of Xhosa plant names from Eastern Cape, South Africa," Bothalia, vol. 29, no. 2, pp. 267-292, 1999.

[11] A. Moteetee and K. L. Seleteng, "A review of medicinal plants used by the basotho for treatment of skin disorders: their phytochemical, antimicrobial and anti-inflammatory potential," African Journal of Traditional, Complementary and Alternative Medicines, vol. 14, no. 5, pp. 121-137, 2017.

[12] W. Mbeng-Otang and I. J. Sagbo, "Plants used for cosmetics in the eastern Cape province of South," Pharmacognosy Reviews, vol. 12, no. 24, pp. 139-156, 2018.

[13] W. Otang-mbeng and I. J. Sagbo, "Gas chromatography-mass spectrometry analysis of the volatile compounds from the ethanol extracts of Bulbine asphodeloides and Helichrysum petiolare," Pharmacognosy Reviews, vol. 11, no. 3, pp. 219-223, 2019.

[14] M. E. A. Qhotsokoane-Lusunzi and P. Karuso, "Secondary metabolites from basotho medicinal plants. I. Bulbine narcissifolia," Journal of Natural Products, vol. 64, no. 10, pp. 1368-1372, 2001.

[15] J. C. Pretorius, S. Magama, P. C. Zietsman, and B.-E. van Wyk, "Growth inhibition of plant pathogenic bacteria and fungi by extracts from selected South African plant species," South African Journal of Botany, vol. 69, no. 2, pp. 186-192, 2003.

[16] I. J. Sagbo and W. Otang-mbeng, "Anti-proliferative and genotoxic activities of the Helichrysum petiolare Hilliard \& B. L. Burtt," Scientia Pharmaceutica, vol. 88, no. 4, p. 49, 2020. 
[17] W. Otang-mbeng and I. J. Sagbo, "Anti-melanogenesis, antioxidant and anti-tyrosinase activities of scabiosa columbaria L," Processes, vol. 8, no. 2, p. 236, 2020.

[18] M. N. Nyambe, T. C. Koekemoer, and M. Van De Venter, "In vitro evaluation of the phytopharmacological potential of sargassum incisifolium for the treatment," Medicines, vol. 6, no. 2, p. 49, 2019.

[19] T. Mosmann, "Rapid colorimetric assay for cellular growth and survival: application to proliferation and cytotoxicity assays," Journal of Immunological Methods, vol. 65, no. 1-2, pp. 55-63, 1983.

[20] S.-B. Shim, N.-J. Kim, and D.-H. Kim, " $\beta$-Glucuronidase inhibitory activity and hepatoprotective effect of $18 \beta$ glycyrrhetinic acid from the rhizomes of Glycyrrhiza uralensis," Planta Medica, vol. 66, no. 1, pp. 40-43, 2000.

[21] M. Kanlayavattanakul and N. Lourith, "Body malodours and their topical treatment agents," International Journal of Cosmetic Science, vol. 33, 2011.

[22] L. T. Dalvi, D. C. Moreira, R. Andrade, J. Ginani, A. Alonso, and M. Hermes-Lima, "Ellagic acid inhibits iron-mediated free radical formation," Spectrochimica Acta Part A: Molecular and Biomolecular Spectroscopy, vol. 173, pp. 910-917, 2017.

[23] J. A. Jaén, L. González, A. Vargas, and G. Olave, "Gallic acid, ellagic acid and pyrogallol reaction with metallic iron," $\mathrm{Hy}$ perfine Interactions, vol. 148, no. 1, pp. 227-235, 2003.

[24] L. Yujing, L. Zhaojiem, H. Hu, Z. Yongliang, and L. Sun, "Metal chelating, inhibitory DNA damage, and anti-inflammatory activities of phenolics from rambutan (Nephelium lappaceum) peel and the quantifications of geraniin and corilagin," Molecules, vol. 23, p. 2263, 2018.

[25] M. L. Bongoura, J. Nsor-Atindana, and Z. H. Ming, "Solvent optimization of antioxidants from foxtail millet species' insoluble fibers and their free radical scavenging properties," Food Chemistry, vol. 141, no. 3, pp. 736-744, 2013.

[26] T. Mercy, R. Sri, and H. Pudji, "Antioxidative activities of various fractions of gedi's leaf extracts (Abelmoschus manihot L. medik)," Agriculture and Agricultural Science Procedia, vol. 9, pp. 271-278, 2016.

[27] N. Pather, The in vitro and in vivo effects of Bulbine frutescens and Bulbine natalensison cutaneous wound healing, Ph.D. Thesis, Faculty of Science University of Witwatersrand, Johannesburg, South Africa, 2009.

[28] S. Huang, Y. Ma, D. Sun, J. Fan, and S. Cai, "In vitro DNA damage protection and anti-inflammatory effects of tartary buckwheats (Fagopyrum tataricum L. Gaertn) fermented by filamentous fungi," International Journal of Food Science \& Technology, vol. 52, no. 9, pp. 2006-2017, 2017.

[29] R. N. Gacche and N. A. Dhole, "Antioxidant and possible antiinflammatory potential of selected medicinal plants prescribed in the Indian traditional System of medicine," Pharmaceutical Biology, vol. 44, no. 5, pp. 389-395, 2006.

[30] P. Hankittichai, P. Buacheen, P. Pitchakarn et al., "Artocarpus lakoocha extract inhibits LPS-induced inflammatory response in RAW 264.7 macrophage cells," International Journal of Molecular Sciences, vol. 21, no. 4, p. 1355, 2020.

[31] T. Q. C. Nguyen, T. Duy Binh, T. L. A. Pham et al., "Antiinflammatory effects of Lasia spinosa leaf extract in lipopolysaccharide-induced RAW 264.7 macrophages," International Journal of Molecular Sciences, vol. 21, no. 10, p. 3439, 2020.

[32] I. J. Sagbo, M. Van De Venter, T. Koekemoer, and G. Bradley, "In vitro antidiabetic activity and mechanism of action of Brachylaena Elliptica (Thunb.) DC," Evidence-Based Complementary and Alternative Medicine, vol. 2018, Article ID 4170372, 13 pages, 2018. 